\title{
The debate for thermal ablation of colorectal cancer pulmonary metastases is heating up
}

\author{
Karin Steinke ${ }^{1,2}$ \\ ${ }^{1}$ Department of Medical Imaging, Royal Brisbane and Women's Hospital, Herston, Queensland, Australia; ${ }^{2}$ University of Queensland School of \\ Medicine, St Lucia, Queensland, Australia
}

Correspondence to: Karin Steinke. University of Queensland School of Medicine, St Lucia 4072, Queensland, Australia. Email: karin.steinke@health.qld.gov.au.

Provenance and Peer Review: This article was commissioned by the Editorial Office, Quantitative Imaging in Medicine and Surgery. The article did not undergo external peer review.

Comment on: Hasegawa T, Takaki H, Kodama H, Yamanaka T, Nakatsuka A, Sato Y, Takao M, Katayama Y, Fukai I, Kato T, Tokui T, Tempaku H, Adachi K, Matsushima Y, Inaba Y, Yamakado K. Three-year survival rate after radiofrequency ablation for surgically resectable colorectal lung metastases: a prospective multicenter study. Radiology 2020;294:686-95.

Submitted Mar 09, 2020. Accepted for publication Mar 20, 2020.

doi: 10.21037 /qims.2020.03.18

View this article at: http://dx.doi.org/10.21037/qims.2020.03.18

Colorectal cancer (CRC) is the third most common cancer worldwide and the fourth most common cause of cancer death. The number of deaths is expected to rise in all countries until 2035, for both colon and rectal cancer by $60 \%$ and $71 \%$ respectively, mainly due to population growth and ageing (1). The highest CRC incidence rates are in Australia, New Zealand, Europe, and North America, and the lowest rates are found in Africa and South-Central Asia. These geographic differences appear to be attributable to differences in socioeconomic status, and to dietary and environmental exposures imposed upon a background of genetically determined susceptibility (2).

Death from CRC is usually a result of metastatic spread. Lung is the second most common site for metachronous CRC metastatic spread, liver being the first. About 20\% of patients present with synchronous metastases, most commonly in the liver, and up to $60 \%$ of the remaining patients develop metastases within 5 years (3). Rectal cancer and left-sided colon cancer are associated with significantly higher rates of lung-only metastases, seen in $10-20 \%$ of patients $(4,5)$. The prognosis of untreated stage IV disease is poor, with an average lifespan of 5-6 months (4). There is extensive data showing survival benefit for metastasectomy for CRC lung metastases, favourable factors being a maximum of 3 metastases, unilateral lesions, lack of thoracic nodal involvement, long disease-free interval (DFI) and no elevated carcinoembryonic antigen (CEA) pre thoracotomy (6). A history of resected liver metastases did not reach statistical significance for poorer outcome, provided there was no evidence of hepatic metastatic involvement at the time of pulmonary metastasectomy (6).

Disease recurrence is common after pulmonary metastasectomy-with $69 \%$ of patients showing new metastases in lung, liver or both; repeat resection carries a better survival than other treatments or palliative care $(7,8)$. The addition of targeted therapy to conventional chemotherapy has been a recent valuable adjunct to the neoadjuvant or adjuvant treatment of the primary colorectal site. However, pulmonary metastases do not respond well to chemotherapy (9).

Recent data on stereotactic body radiation therapy (SBRT) of pulmonary oligometastatic disease shows a significantly lower local control rate for CRC primaries compared to other primary sites with 24-month cumulative incidence rates of local failure above $40 \%$ (10-12).

Heat based thermal ablation for both primary and secondary lung malignancies has been performed since 
the early 2000s, with most publications considering radiofrequency ablation (RFA). A later development is microwave ablation (MWA), used on a wider scale in the clinical setting for the past 10 years. No significant difference in the outcome of CRC metastases treated with RFA compared to MWA has been reported in early publications, with promising 3 -year overall survival rates of $58 \%$ and $64 \%$ respectively, and comparable complication rates (13). However, more recent publications show statistically significant better local tumor control for MWA compared with RFA and laser-induced thermotherapy (LITT) (14). Complications after lung thermal ablation are usually self-limiting. Grade 3 or 4 adverse events are reported to occur in less than $10 \%$ of patients and include aseptic pleuritis, pneumonia, abscess, bleeding requiring blood transfusion, pneumothorax, broncho-pleural fistula requiring pleurodesis, thermal injury of nerves and diaphragm, tumor seeding, and pseudoaneurysm formation (15). The incidence of pneumothorax requiring a chest drain appears to be linked to the number of treated lesions and the length of the procedure (16). The incidence of pneumonia and abscess lies below $2 \%$ and is more prone in patients with older age and pre-existing inflammatory lung disease and in patients who have received prior radiotherapy (15).

The long-term follow-up of a large patient group (157 patients) with RFA of their CRC lung metastases (434 lesions) shows very promising results of $20 \% 5$-year survival, especially on the background of $3 / 4$ of the patient cohort having had liver and/or peritoneal resection prior to their lung RFA. Interestingly, opposed to many other studies, neither lesion size, nor lesion number, nor preablation CEA were prognostic factors (17).

The largest report on RFA of lung metastases included 566 consecutive patients with 1037 lung metastases from colon (34\%), rectum (18\%), renal (12\%), soft-tissue sarcoma (9\%) and other miscellaneous origins (28\%). A poorer overall survival (OS) occurred when the size exceeded $2 \mathrm{~cm}$ and the number of metastases 3 . A very encouraging $91.6 \%$ local control rate at 3 years for metastases not exceeding $3 \mathrm{~cm}$ was reported (18). When looking at the subpopulation of 293 CRC lung metastases, the 1-, 3-, and 5-year OSs were $92.9 \%, 76.1 \%$, and $56.0 \%$. These results are within the range of the best results achieved by surgery-a 5 -year OS of $53.5 \%$ reported in a multi-center registry of lung metastasectomy for CRC (19); a 5-year OS of 32.7-56\% in a literature review looking at 11 publications with 1307 patients, with a 39.1-67.8\% 5-year OS if only R0 resection was considered (20). For those patients eligible for lung metastasectomy, surgical management of recurrences is limited given the technical difficulties inherent to repeat thoracotomy and loss of lung volume.

The first prospective multicentre trial by Hasegawa et al. (21) evaluating the long-term efficacy of percutaneous RFA of CRC lung metastases parallels and even exceeds the best reported local control rate, with a primary $91 \%$ local control rate, secondary 3-year local control rate of $98 \%$ with successful re-ablation in 5 of 6 patients with local recurrence and a very favourable 3-year OS rate of $84 \%$. Careful selection of patients-metastases smaller than $3 \mathrm{~cm}$ in maximum diameter, $70 \%$ of patients with single lung metastasis, $83 \%$ of the metastases in peripheral location, and stringent exclusion criteria (concomitant liver metastasis, nodal metastasis, location of target lesion adjacent to hilum or major organs, and previous radiotherapy) contributed to this promising outcome. This very favourable 3 -year OS compared to the $35-72 \%$ reported in a recent systematic review on percutaneous RFA in CRC lung metastases (22) is likely a result of careful selection of patients in Hasegawa et al.'s study, possibly aided to a certain extent by the low rate of pathologic confirmation of the treated lesions of only $7 \%$, raising the possibility that some of the lesions may not have represented colorectal metastases. It is however common practice to favour gestalt reasoning and waive tissue diagnosis in the typical scenario of advanced CRC with new and or enlarging spherical peripheral lung nodule(s). Of note that there was one (of 88 RFA sessions) grade 5 adverse event with no grade 3 or 4 events in Hasegawa et al.'s study (21), with an even lower mortality rate of $1 / 610$ and major complications reported between $0-8 \%$ in the mentioned systematic review (22).

Opposed to RF heating which is limited in areas of low electrical conductivity resulting in tissues being adequately heated only immediately adjacent to the RF electrode, MW heating occurs via dielectric hysteresis by forcing polar molecules-primarily $\mathrm{H}_{2} \mathrm{O}$ - to increase their kinetic energy by continuously realigning with the oscillating field. Microwaves are capable of propagating through tissues with low electrical and thermal conductivity and high impedance, such as the lung, also penetrating through charred and desiccated tissue building up around heat-based ablation applicators. MWA produces faster and more homogeneous lethal heating of larger tissue volumes with little susceptibility to heat-sink effects and without the need of grounding pads or other ancillary components (23). By virtue of its direct heating and more predictable heat profile, MWA is expected to produce more favourable outcomes than RFA, with quicker 
procedures, lower local recurrence rates and the option of successfully targeting larger lesions (24-28).

There is enough evidence to support the belief that thermal ablation of CRC lung metastases not only prolongs survival, but even provides cure in a select sub-population with favourable parameters. It carries less morbidity than surgery, is superior to SBRT, is cost-effective, has minimal impact on pulmonary function and quality of life, and, above all, is repeatable.

Complications of percutaneous lung ablations are usually minor and self-limiting; in skilled hands, many major complications can be circumvented, i.e., by creating an artificial pneumothorax or injecting fluid to displace the ablation area from critical structures and by avoiding unfavourable trajectories-potentially aided by computerassisted navigation of antenna insertion, as already successfully performed in the liver (29).

The combination of thermal ablation of CRC lung metastases with immune-modulating treatment, either injected into the target lesion or systemically administered, is an exciting avenue worth exploring (30).

The hope for prospective randomized controlled trials directly comparing the local treatment options of CRC lung metastases is rather bleak. The number needed to treat is way too high to reach statistical significance, even if aiming for non-inferiority, there are too many different ablation systems on the market with different antennae and ablation protocols. Well-designed studies in similar scenarios such as STARS and ROSEL, comparing local treatment of early stage primary lung cancer, had to be prematurely discontinued due to poor accrual numbers (31).

Hasegawa et al.'s well designed prospective multicentre observational study on long-term outcome of RFA in CRC pulmonary metastases adds to the myriad of retrospective studies, meta-analyses, and review articles showing the efficacy of heat-based percutaneous thermal ablation of CRC lung metastases.

In an era of limited resources, an aging population and an increasing incidence of CRC in the industrialised world, 'choosing wisely' is paramount—offering select patients effective, efficient, affordable and repeatable local treatment options for their CRC pulmonary metastases with minimal impact on quality of life. This is a task CT-guided thermal ablation can deliver.

\section{Acknowledgments}

Thanks to Peter Scally for proof-reading the manuscript.
Funding: None.

\section{Footnote}

Conflicts of Interest: The author has completed the ICMJE uniform disclosure form (available at http://dx.doi. org/10.21037/qims.2020.03.18). The author has no conflicts of interest to declare.

Open Access Statement: This is an Open Access article distributed in accordance with the Creative Commons Attribution-NonCommercial-NoDerivs 4.0 International License (CC BY-NC-ND 4.0), which permits the noncommercial replication and distribution of the article with the strict proviso that no changes or edits are made and the original work is properly cited (including links to both the formal publication through the relevant DOI and the license). See: https://creativecommons.org/licenses/by-nc-nd/4.0/.

\section{References}

1. Araghi M, Soerjomataram I, Jenkins M, Brierley J, Morris E, Bray F, Arnold M. Global trends in colorectal cancer mortality: projections to the year 2035. Int J Cancer 2019;144:2992-3000.

2. Colorectal cancer: Epidemiology, risk factors, and protective factors. Available online: https://www.uptodate. com/contents/colorectal-cancer-epidemiology-riskfactors-and-protective-factors

3. Pretzsch E, Bösch F, Neumann JP, Ganschow P, Bazhin A, Guba M, Werner J, Angele M. Mechanisms of Metastasis in Colorectal Cancer and Metastatic Organotropism: Hematogenous versus Peritoneal Spread. J Oncol 2019;2019:7407190.

4. Scheithauer W, Rosen H, Kornek GV, Sebesta C, Depisch D. Randomised comparison of combination chemotherapy plus supportive care with supportive care alone in patients with metastatic colorectal cancer. BMJ 1993;306:752-5.

5. Labianca R, Beretta GD, Kildani B, Milesi L, Merlin F, Mosconi S, Pessi MA, Prochilo T, Quadri A, Gatta G, de Braud F, Wils J. Colon cancer. Crit Rev Oncol Hematol 2010;74:106-33.

6. Gonzalez M, Poncet A, Combescure C, Robert J, Ris HB, Gervaz P. Risk factors for survival after lung metastasectomy in colorectal cancer patients: a systematic review and meta-analysis. Ann Surg Oncol 2013;20:572-9.

7. Suzuki H, Kiyoshima M, Kitahara M, Asato Y, Amemiya R. Long-term outcomes after surgical resection of pulmonary metastases from colorectal cancer. Ann Thorac Surg 
2015;99:435-40.

8. Guerrera F, Mossetti C, Ceccarelli M, Bruna MC, Bora G, Olivetti S, Lausi PO, Solidoro P, Ciccone G, Ruffini E, Oliaro A, Filosso PL. Surgery of colorectal cancer lung metastases: analysis of survival, recurrence and re-surgery. J Thorac Dis 2016;8:1764-71.

9. Inoue Y, Miki C, Hiro J, Ojima E, Yamakodo K, Takeda K, Kusunoki M. Improved survival using multi-modality therapy in patients with lung metastases from colorectal cancer: A preliminary study. Oncol Rep 2005;14:1571-6.

10. Binkley MS, Trakul N, Jacobs LR, von Eyben R, Le QT, Maxim PG, Loo BW Jr, Shultz DB, Diehn M. Colorectal Histology Is Associated With an Increased Risk of Local Failure in Lung Metastases Treated With Stereotactic Ablative Radiation Therapy, Int J Radiat Oncol Biol Phys 2015;92:1044-52.

11. Jingu $\mathrm{K}$, Matsushita $\mathrm{H}$, Yamamoto $\mathrm{T}$, Umezawa R, Ishikawa Y, Takahashi N, Katagiri Y, Takeda K, Kadoya N. Stereotactic Radiotherapy for Pulmonary Oligometastases From Colorectal Cancer: A Systematic Review and Meta-Analysis. Technol Cancer Res Treat 2018;17:1533033818794936.

12. Takeda A, Kunieda E, Ohashi T, Aoki Y, Koike N, Takeda T. Stereotactic body radiotherapy (SBRT) for oligometastatic lung tumors from colorectal cancer and other primary cancers in comparison with primary lung cancer. Radiother Oncol 2011;101:255-9.

13. Gonzalez Aguirre AJ, Boas FE, Erinjeri JP, Petre E, Sofocleous CT, Solomon SB. Comparison of microwave and radiofrequency ablation of colon cancer pulmonary metastases. Oral presentation at SIR, Washington, DC, 2017-03-06. JVIR 2017;28:S85.

14. Vogl TJ, Eckert R, Naguib NN, Beeres M, Gruber-Rouh T, Nour-Eldin NA. Thermal ablation of colorectal lung metastases: retrospective comparison among laser-induced thermotherapy, radiofrequency ablation, and microwave ablation. AJR Am J Roentgenol 2016;207:1340-9.

15. Kashima M, Yamakado K, Takaki H, Kodama T, Yamada T, Uraki J, Nakatsuka A. Complications after 1000 lung radiofrequency ablation sessions in 420 patients: a single center's experiences. AJR Am J Roentgenol 2011;197:W576-80.

16. Yan TD, King J, Sjarif A, Glenn D, Steinke K, Morris DL. Percutaneous radiofrequency ablation of pulmonary metastases from colorectal carcinoma: prognostic determinants for survival. Ann Surg Oncol 2006;13:1529-37.

17. Ferguson J, Alzahrani N, Zhao J, Glenn D, Power M,
Liauw W, Morris DL. Long term results of RFA to lung metastases from colorectal cancer in 157 patients. Eur J Surg Oncol 2015;41:690-5.

18. de Baère T, Aupérin A, Deschamps F, Chevallier P, Gaubert Y, Boige V, Fonck M, Escudier B, Palussiére J. Radiofrequency ablation is a valid treatment option for lung metastases: experience in 566 patients with 1037 metastases. Ann Oncol 2015;26:987-91.

19. Iida T, Nomori H, Shiba M, Nakajima J, Okumura S, Horio H, Matsuguma H, Ikeda N, Yoshino I, Ozeki Y, Takagi K, Goya T, Kawamura M, Hamada C, Kobayashi K, Metastatic Lung Tumor Study Group of Japan. Prognostic factors after pulmonary metastasectomy for colorectal cancer and rationale for determining surgical indications: a retrospective analysis. Ann Surg 2013;257:1059-64.

20. Pfannschmidt J, Hoffmann H, Dienemann H. Reported outcome factors for pulmonary resection in metastatic colorectal cancer. J Thorac Oncol 2010;5:S172-8.

21. Hasegawa T, Takaki H, Kodama H, Yamanaka T, Nakatsuka A, Sato Y, Takao M, Katayama Y, Fukai I, Kato T, Tokui T, Tempaku H, Adachi K, Matsushima Y, Inaba Y, Yamakado K. Three-year survival rate after radiofrequency ablation for surgically resectable colorectal lung metastases: a prospective multicenter study. Radiology 2020;294:686-95.

22. Lyons NJ, Pathak S, Daniels IR, Spiers A, Smart NJ. Percutaneous management of pulmonary metastases arising from colorectal cancer: a systematic review. Eur J Surg Oncol 2015;41:1447-55.

23. Lubner MG, Brace CL, Hinshaw JL, Lee FT Jr. Microwave tumor ablation: mechanism of action, clinical results, and devices. J Vasc Interv Radiol 2010;21:S192-203.

24. Smith SL, Jennings PE. Lung radiofrequency and microwave ablation: a review of indications, techniques and post-procedural imaging appearances. Br J Radiol 2015;88:20140598.

25. Sidoff L, Dupuy DE. Clinical experiences with microwave thermal ablation of lung malignancies. Int J Hyperthermia 2017;33:25-33.

26. Ferguson CD, Luis CR, Steinke K. Safety and efficacy of microwave ablation for medically inoperable colorectal pulmonary metastases: Single-centre experience. J Med Imaging Radiat Oncol 2017;61:243-9.

27. Kurilova I, Gonzalez-Aguirre A, Beets-Tan RG, Erinjeri J, Petre EN, Gonen M, Bains M, Kemeny NE, Solomon SB, Sofocleous CT. Microwave Ablation in the Management of Colorectal Cancer Pulmonary Metastases. Cardiovasc 
Intervent Radiol 2018;41:1530-44.

28. Prud'homme C, Deschamps F, Moulin B, Hakime A, AlAhmar M, Moalla S, Roux C, Teriitehau C, de Baere T, Tselikas L. Image-guided lung metastasis ablation: a literature review. Int J Hyperthermia 2019;36:37-45.

29. Lachenmayer A, Tinguely P, Maurer MH, Frehner L, Knöpfli M, Peterhans M, Weber S, Dufour JF, Candinas D, Banz V. Stereotactic image-guided microwave ablation of hepatocellular carcinoma using a computer-assisted navigation system. Liver Int 2019;39:1975-85.

30. Bäcklund M, Freedman J. Microwave Ablation and Immune Activation in the Treatment of Recurrent

Cite this article as: Steinke K. The debate for thermal ablation of colorectal cancer pulmonary metastases is heating up. Quant Imaging Med Surg 2020;10(5):1169-1173. doi: 10.21037/ qims.2020.03.18
Colorectal Lung Metastases: A Case Report. Case Rep Oncol 2017;10:383-7.

31. Chang JY, Senan S, Paul MA, Mehran RJ, Louie AV, Balter P, Groen HJ, McRae SE, Widder J, Feng L, van den Borne BE, Munsell MF, Hurkmans C, Berry DA, van Werkhoven E, Kresl JJ, Dingemans AM, Dawood O, Haasbeek CJ, Carpenter LS, De Jaeger K, Komaki R, Slotman BJ, Smit EF, Roth JA. Stereotactic ablative radiotherapy versus lobectomy for operable stage I non-small-cell lung cancer: a pooled analysis of two randomised trials. Lancet Oncol 2015;16:630-7. 